\title{
Employees' self-determined motivation, transformational leadership and work engagement
}

\author{
Jeremy Chua and Oluremi B. Ayoko* \\ The University of Queensland, St Lucia, QLD 4072, Australia \\ *Corresponding author. Email: r.ayoko@business.uq.edu.au
}

(Received 7 November 2017; revised 1 October 2018; accepted 13 November 2018; first published online 17 January 2019)

\begin{abstract}
While research on the role of employees' characteristics as core to transformational leadership theory is burgeoning, limited research has focused on the differing aspects of employees' self-determined motivation as mediating mechanism through which transformational leadership may impact outcomes. Drawing on the self-determined theory of motivation, we build and test a theoretical model linking employees' perceptions of transformational leadership with engagement through an intervening variable of differing aspects of employees' self-determined motivation. Data from a sample of 155 participants revealed that employees' perceptions of transformational leadership were positively related to employees' self-determined motivation (intrinsic, autonomous, and controlled) and work engagement. Specifically, self-determined motivation (intrinsic, autonomous) was positively linked with work engagement while intrinsic, autonomous and controlled dimensions of self-determined motivation mediated the relationship between transformational leadership and work engagement. We discuss the theoretical and practical implications of the results.
\end{abstract}

Keywords: leadership; job engagement; motivation; research methods; quantitative methods

\section{Introduction}

There is an overwhelming empirical evidence to support the notion that transformational leadership (TL) is connected with a wide range of positive organizational outcomes (Judge \& Piccolo, 2004; Kovjanic, Schuh, Jonas, van Quaquebeke, \& van Dick, 2012). Importantly, research findings suggest that TL influences, broadens, and elevates followers' goals and provides them with confidence to perform beyond their expectations (Bass \& Avolio, 1994; Conchie, 2013; Piccolo \& Colquitt, 2006). In this regard, Kovjanic and colleagues (2012) summarized the three mechanisms by which transformational leaders are able to achieve these positive outcomes: followers' self-perception (Schaubroeck, Lam, \& Cha, 2007), followers attitudes to the leader (Jung, Yammarino, \& Lee, 2009), and followers' perceptions for their job (Arnold, Turner, Barling, Kelloway, \& McKee, 2007). These studies demonstrate that effective leadership is not a sole responsibility of the leader alone but also the followers' behaviors (Aw \& Ayoko, 2017) and that information processing (Lord \& Emrich, 2000) may also impact followers' perception. These, in turn, contribute to shaping the leaders' behaviors and consequences. Nevertheless, there are suggestions that the role of the follower in the leadership process is not clearly understood (Crossman \& Crossman, 2011; Küpers, 2007) and that followership theory has been 'given a short shrift' (Uhl-Bien, Riggio, Lowe, \& Carsten, 2014: 83). By extension, we argue that the central tenet in TL (e.g., followers' needs, see Kovjanic et al., 2012) and followers' perceptions of the leader seem to have been overlooked. Yet, the evaluation and acceptance of a leader is driven by the followers' perspectives, attitudes, and perceptions (Felfe \& Schyns, 2006, 2010). 
While followership has attracted less attention (compared with leadership) in literature, Crossman and Crossman (2011) propose that the current climate of shared and distributed or even dispersed leadership (where individuals have opportunity to be followers and leaders concurrently; Horsfall, 2001) implies that the notion of followership is relevant for both researchers and practitioners. In this respect, followership has been defined severally (for a review, see Baker, 2007; Crossman \& Crossman, 2011). However, in the current research, we follow Carsten, Uhl-Bien, West, Patera, and McGregor (2010) to define followership as a relational role in which followers influence leaders to contribute to the improvement and attainment of individual, group, and organizational objectives (see also Kelley, 1988; Wortman, 1982). In this way, followership is complementary to leadership (Agho, 2009) and consequently, the understanding of followership and how followers inform the leaders' competence, the leadership process, and organizational effectiveness (Rosenbach \& Taylor, 2006) is critical.

In this regard, researchers (e.g., Avolio, Zhu, Koh, \& Bhatia, 2004; Bono \& Judge, 2003; Kojvanic et al., 2012; Trépanier, Fernet, \& Austin, 2012) have been interested in the underlying mechanisms through which leaders (e.g., TL) might exert influence on their followers. Additionally, Felfe and colleagues $(2006 ; 2010)$ argue that the followers' perceptions of leadership might shape the leaders' influence. Findings from this line of research support their argument and demonstrate that employees' perceptions of their leader are key determining factors in how the leader is evaluated and accepted in a given context (Felfe \& Schyns, 2006). Nevertheless, the above studies have focused on followers' personality in predicting their perceptions of TL. In the current paper, we refer to followers' perception as the way the followers process, interpret, or make subjective meaning from the actions, behaviors, or influence processes of the leader (see Felfe \& Schyns, 2010). We argue that the followers' perceptions of their leader are central for how they (i.e., followers) respond to the leader's influence and more importantly become more engaged in work and motivation.

Moreover, Trépanier, Fernet, and Austin (2012) investigated how the quality of relationship predicts perceptions of TL through autonomous motivation and self-efficacy. In this regard, motivation and self-efficacy were conceptualized as antecedents to the perceptions of TL and even then, their focus was on autonomous motivation alone. Similarly, Kovjanic and colleagues (2012) examined TLs' fulfillment of followers' basic needs (i.e., for competence, relatedness, and autonomy) as mediators in the link between TL and employees outcomes of job satisfaction, selfefficacy, commitment to the leader, and performance (see also Kovjanic, Schuh, \& Jonas, 2013). While the above studies improve our understanding of the antecedents of followers' perceptions and the role of autonomy, we still do not have a complete picture of the nature of employees' perceptions of their TL and how these perceptions might activate differing dimensions of follower's motivation (not just autonomy) for higher levels of work engagement.

In this regard, Kovjanic et al., (2012) and Kovjanic, Schuh, \& Jonas (2013) focus on how the leaders' fulfillment of followers' needs might be an underlying mechanism for followers' commitment to leadership and performance. In contrast, our study highlights the followers' perceptions of the TL (not the leader) as a key driver of their own (i.e., followers) self-motivation. We argue that the followers' self-motivation is an important mechanism through which followers' work engagement is fostered. In other words, Kovjanc and colleagues (2012) conceptualize followers' need satisfaction (by the TL) as mediators, our study focuses on the followers' perceptions of TL as triggering followers' self-motivation which, in turn, we depicted as the mechanism through which the followers' perceptions of TL are linked with their work engagement (see Figure 1). Altogether our study departs from examining the antecedents of followers' perception of TL such as personality (Felfe \& Schyns, 2006, 2010; Schyns \& Felfe, 2006) and followers' psychological need for autonomy (Kovajanic et al., 2012; Trépanier, Fernet, \& Austin, 2012) to predict engagement. Rather, we focus on the employees' perceptions of TL and examine how these perceptions might trigger followers' full range of self-determined motivation (SDM) (i.e., intrinsic motivation, controlled, autonomous, and amotivation) to predict employees' engagement. 


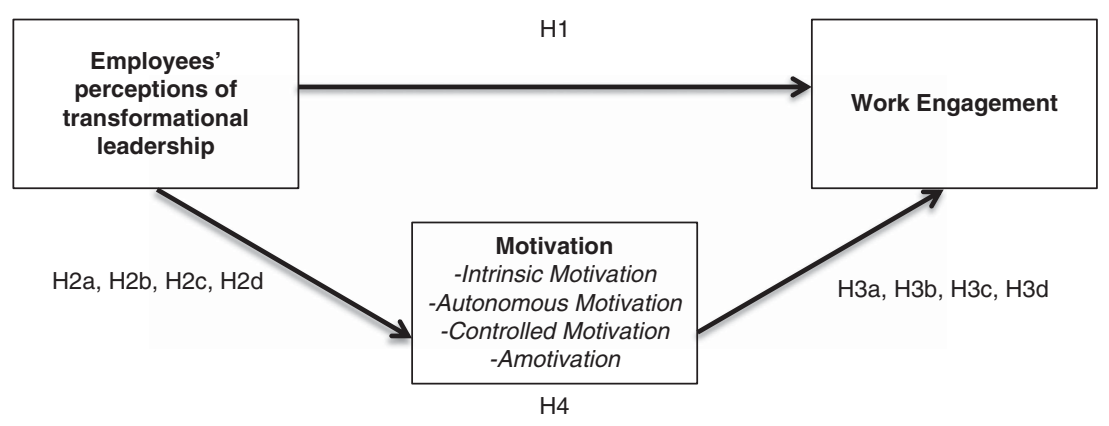

Figure 1. The model of the relationship between employees' perceptions of transformational leadership, motivation, and work engagement

By examining the link between follower's perceptions of TL, motivation, and engagement, we contribute to literature in three major ways. First, since Kelley's (1992) conceptualization of the role of the followers, the place of the followers in the leadership process (Riggio, Challeff, \& Lipman-Blumen, 2008) is emerging (Baker, 2007; Crossman \& Crossman, 2011; Howell \& Shamir, 2005; Wang, Hinrichs, Prieto, \& Black, 2010). The current study extends research on TL by empirically investigating how the way the followers perceive TL may be connected with the extent to which the followers are involved in work engagement. Our study speaks to the critical need to have a more in-depth understanding of the role of followers in the leadershipfollowership process.

Second, we know that TL builds a sense of self-motivation in their followers (Bass, 1985). Yet, we do not know how the followers' perceptions of TL assist in activating dimensions of selfmotivation. We draw on the self-determination theory (SDT), a theory that makes distinctions between differing types of motivation, to gain a better insight into how the employees' perceptions of the enactment of TL might elicit differing employees' motivation. As previously established, while studies have examined psychological needs of competence, autonomy, and selfefficacy as mechanisms through which perception of leadership might influence outcomes (e.g., engagement), studies that have simultaneously examined the link between followers' perceptions of TL and all the dimensions of SDM are rare. The current study fills this void. By simultaneously examining all dimensions of SDM, we anticipate that our findings should assist in determining which aspect(s) of SDM is sensitive to employees' perceptions of TL, thereby increasing the predictive power of perception of TL for followers' outcomes. This, in turn, will assist training (e.g., impression management) for TL, thus advancing literature on TL. Moreover, the simultaneous examination of all dimensions of SDT as mediators in the link between the perceptions of TL and work engagement advances the SDT literature, as managers will now be able to isolate which particular dimension of SDT is required to foster work engagement in the context of TL.

Third, we are aware that self-motivation is critical for improved employees' performance, persistence, and creativity (Deci \& Ryan, 1985a). Indeed, Gagné, Forest, Gilbert, Aubé, Morin, and Malorni (2010: 426) argues that 'SDT has just recently begun to be applied to the work domain.' By explicating the mediating role of all dimensions of SDM in the relationship between perceptions of TL and work engagement, we extend the literature on SDT in the work domain. In particular, we add to studies examining process (e.g., mediators; Liu, Zhu \& Yang, 2010) and move beyond the isolation of the direct effects of TL behaviors and employees' outcomes. Specifically, we argue that the impact of the followers' perceptions of transformational behavior on followers' outcomes may be largely explained by SDM, thus clarifying the relationship between perceptions of their TL and work engagement. Altogether, we expect the outcomes of our research to advance knowledge in how the followers (e.g., followers' perceptions of TL) contribute to the leadership process and the achievement of organizational goals. 


\section{Conceptual background and hypotheses development}

\section{Transformational leadership}

We employ both TL and SDT as theoretical anchors for the current research. TL is defined as a leadership style that inspires employees or followers to change their beliefs, values, capabilities, and motives to raise their performance beyond self-interest for the benefit of the organization (Avolio, 1999) while building a sense of self-motivation in their employees (Bass, 1985). They do this in a number of ways. First, given that TL assists in linking the collective goals of the team or organization to the goals of each individual, TL makes it likely that individuals would autonomously pursue these goals (Shamir, House, \& Arthur, 1993). Second, transformational leaders encourage individuals to develop new approaches to efficiently accomplish their tasks, offering them freedom and autonomy in doing so (Kovjanic et al., 2012). Third, this form of leadership broadens individual responsibilities and encourages individuals to assume greater challenges in the workplace (Avolio, 2005). In this way, transformational leaders help their employees to be better prepared to meet higher expectations and take on difficult challenges (Avolio, 1999). Finally, TL influences employees through value internalization and helps individuals become engaged with their work (Bono \& Judge, 2003). Thus, through value internalization, employees see their work as congruent with their ideals and values (Bono \& Judge, 2003). Altogether, through the process of shaping employees' personal values, we argue that transformational leaders may impact employees' SDM.

\section{Self-Determination Theory (SDT)}

SDT is an approach to human motivation and personality (Deci \& Ryan, 1985b; Ryan \& Deci, $2000 \mathrm{~b}$ ), and it states that conditions supporting an individual's experience of autonomy, competence and relatedness foster the most volitional and highest quality of motivation that will result in enhanced performance, persistence, and creativity (Deci \& Ryan, 1985a). In this regard, autonomy, competence, and relatedness are core to the basic psychological needs theory (Ryan \& Deci, 2000b) which posits that the satisfaction of the above basic needs is critical for human thriving, while the frustration of the basic needs may result in maladjustment and psychopathology (Vansteenkiste \& Ryan, 2013). The basic psychological needs are the nutriments that are cross-developmentally and cross-culturally required for psychological froth, integrity, and well-being (Deci \& Ryan, 2000). Yet, basic needs differ from motivation because former involves the reception of the psychological nutriments that facilitate growth and well-being, while the latter is the quality of experience that energizes the behaviors.

Specifically, motivation is a set of energetic forces that originates both within and beyond an individual's being, to initiate work-related behaviors and to determine its form, direction, intensity, and duration (Pinder, 1998). SDT posits that individuals engage in activities they find interesting, optimally challenging, or aesthetically pleasing (Tremblay, Blanchard, Taylor, Pelletier, \& Villeneuve, 2009). Activities that are not experienced in this manner are unlikely to be performed unless there are external pressures or extrinsic reasons (e.g., rewards; see Ryan \& Deci, 2002). The quality of individuals' motivation is therefore higher for activities that they find interesting or have autonomy but lower for activities driven by extrinsic or controlling factors. Thus, SDT is premised on the 'nature' of motivation and whether the individual is selfdetermined in being motivated (Tremblay et al., 2009).

SDT also proposes that motivation lies on a continuum ranging from amotivation, extrinsic motivation to intrinsic motivation (Ryan \& Deci, 2000b). At the beginning of the continuum is amotivation that refers to the state of being unmotivated or lacking the willingness or intention to act. Employees go through the motion resulting from not valuing an activity (Ryan \& Deci, 2000b) and lacking the efficacy to perform an activity (Bandura, 1986). At the opposite end of the continuum is intrinsic motivation which is described as the performance of an activity for its 
inherent satisfaction. Intrinsic motivation is an exemplar of self-determination (Ryan \& Deci, 2000b).

In between the extreme poles of the continuum lies extrinsic motivation that can be controlled or autonomous. On the one hand, controlled motivation emanates from self-imposed pressures and is concerned with behaviors related to the desire to maintain self-esteem, please others, or obey commands (Ryan \& Deci, 2000b). On the other hand, autonomous motivation is related to actions arising from or congruent with one's self (Ryan \& Connell, 1989) and reflects one's values or interests. Altogether, extrinsic motivation are behaviors performed to fulfill the requirement of an external demand or reward and are behaviors enacted to avoid guilt, anxiety, and to attain ego and enhancement (Ryan \& Deci, 2000b). In this case, people are motivated to demonstrate ability and worth and while they are internally driven, these behaviors are performed to meet some external requirements that may not be fully experienced as part of the self.

Also, extrinsic motivation can be in the form of integrated regulation (i.e., regulations that are completely imbibed by the self and are in alignment with one's values and needs). While integrated regulation behaviors share some features of intrinsic motivation, they are extrinsic because they fulfill separable outcomes. This means that extrinsic motivation can be autonomous and self-determined and therefore, Ryan and Deci (2000) reiterate that some studies combine identified, integrated, and intrinsic motivation behaviors as an autonomous composite. In a series of studies conducted by Sheldon and Elliot (1999), they demonstrated that autonomous motivation was linked with goal-directed effort, goal-attainment, and satisfaction with goal achievement. Thus, it would be logical to expect that individuals who possess SDM (autonomous or intrinsic) will be more effective at work than the individuals with controlled motivation. Altogether, we integrate the literature on TL, SDM, and work engagement to build a conceptual model (Figure 1) that depicts employees' perceptions of their TL behaviors as directly linked to the various aspects of their motivation and work engagement. The model also depicts dimensions of motivation as mediators in the relationship between perceptions of TL and work engagement. Assessing dimensions of SDM should assist us in gaining an in-depth understanding of their distinct role in followers' engagement in the context of TL.

\section{Perceptions of TL}

Kelley $(1992,2008)$ describes an effective follower as being self-motivated and independent. This is because while good leadership is associated with higher levels of employees' motivation, leaders do not motivate employees but employees motivate themselves (Hughes, 1998). We argue that individuals make a choice to take responsibility for his/her work, given the perceptions they hold about the leaders (Carsten, Uhl-Bien, West, Patera, \& McGregor, 2010). In this respect, Piccolo and Colquitt (2006) demonstrate that employees' perceptions of their followers are connected with their perceptions of basic job conditions such as variety, identity, and significance. We extend this notion to employees perceptions of TL and work engagement.

We focus on the employees' perceptions of TL for two reasons. First, unlike TL, transactional leadership shifts control from the follower to the leader (Burns, 1998). Similarly, and contrary to the functions of TL, the laissez-faire leadership is demotivating and associated with stress, conflict, and reduced SDM (Bashshur, Hernández, \& González-Romá, 2011). Second, TL is related to the subjective perceptions of employees or followers (Ilies, Judge, \& Wagner, 2006). This is because transformational leaders act as role models for their employees (Avolio \& Bass, 2004), and research evidence shows specific TL behaviors are connected to motivation for safety compliance (Conchie, 2013). Rather than investigating TL and motivation, we focus on employees ' perceptions of TL and how these perceptions might trigger differing dimensions of employees' SDM for their work engagement. 


\section{Employees' perceptions of TL and work engagement}

TL behaviors comprise idealized influence, inspirational motivation, individual consideration, and intellectual stimulation (Avolio, Bass, \& Jung, 1999). Idealized influence and inspirational motivation relate to the leader's ability to formulate and articulate a vision and/or a challenging goal for their subordinates (Dionne, Yammarino, Atwater, \& Spangler, 2004), while activating employees' trust and identification with the leader. Similarly, TL's inspirational motivation provides employees with a sense of purpose and challenge in their work (Bass, Avolio, Jung, \& Berson, 2003), while individualized consideration portrays TL as attending to and addressing employees' specific needs for achievement and growth (Bass, 1985). Finally, leaders' intellectual stimulation behaviors arouse employees to approach problems from new perspectives (Kark, Shamir, \& Chen, 2003). Barling and colleagues (2010) propose that given positive perceptions of their leader, employees may be more likely to exert effort in their work due to greater commitment to the leader. Altogether, we expect that the followers' perceptions of TL behaviors will trigger followers' engagement.

Indeed, scholars theorize that TL is positively related to work engagement (Macey \& Schneider, 2008), and emerging empirical studies (e.g., Tims, Bakker, \& Xanthopoulou, 2011) are just beginning to validate this link. However, studies examining the connection between TL and work engagement do so from the leaders' perspective. We depart from existing research by examining the followers' perceptions of TL and its connection with followers' engagement.

Work engagement is described as vigor, dedication, and absorption (Schaufeli, Salanova, González-Romá, \& Bakker, 2002). Individuals who demonstrate vigor possess high levels of energy and mental resilience in the face of difficulties, while dedicated individuals have a sense of significance, enthusiasm, inspiration, pride, and challenge but possess strong personal identification with their job (Schaufeli et al., 2002). Also, absorption is characterized as being fully concentrated and engrossed in one's work. In this respect, three conditions are necessary for the activation of work engagement: psychological meaningfulness, safety, and availability (Kahn, 1990). Psychological meaningfulness is a perception of returns on investments for exerted efforts (Kahn, 1990), while psychological safety is the ability to display one's self and behave without inhibition or fear for negative consequences to self-image or career (Kahn, 1990). Furthermore, psychological availability at work is to be physically and emotionally ready to engage at a particular moment regardless of the distractions around (Kahn, 1990). We argue that the perceptions of transformational behaviors (e.g., idealized influence and intellectual stimulation) may encourage employees to experience psychological safety.

Likewise, employees who perceive that their leaders address their needs for growth should experience meaning in what they do and this, in turn, should enhance their work engagement. Similarly, employees who perceive individualized consideration from their leaders should also cope with psychological demands at work that should enable them to be psychologically available to engage their work fully. Also, given that transformational leaders are inspiring and visionary (Schaufeli \& Salanova, 2008), their employees will be more likely to work harder to realize the vision prescribed by these leaders (Nübold, Muck, \& Maier, 2013) while experiencing higher levels of work engagement. Thus:

Hypothesis 1: Employees' perceptions of leaders' TL behavior are positively related to the employees' work engagement.

\section{Employees' perceptions of TL and motivation}

TL stimulates employees to change their self-concept, beliefs, values, capabilities, and motives while helping them perform beyond their expectations (Bass et al., 2003). Employees who perceive TL's behaviors will also be motivated intrinsically because they will experience a change in their self-concept, beliefs, and values to align with that of their leader's. Also, TL offers 
individuals a purpose that transcends their short-terms goals and helps them to focus on higher order intrinsic needs (Judge \& Piccolo, 2004). Thus, we anticipate that employees who perceive higher levels of TL behaviors will also be intrinsically driven while experiencing higher levels of motivational autonomy at work. Furthermore, by appealing to employees' common ideals and moral values, employees identify with the needs of the leader (Judge \& Piccolo, 2004). This happens when attractive goals that use universalistic values and appeal to individuals are communicated (Bass, 1985). Employees are thus more likely to have a congruent perception of the set goals and their personal values as they accept and internalize the leaders' goals as their own (Bono \& Judge, 2003). Given SDT, we argue that the leaders of such employees are more likely to activate in the employees an autonomous than controlled motivation. Thus:

Hypothesis 2a: Employees' perceptions of TL behaviors are positively related to the employees' intrinsic motivation.

Hypothesis 2b: Employees' perceptions of TL behaviors are positively related to the employees' autonomous motivation.

Controlled motivation involves the use of contingent rewards and punishment. However, transformational leaders motivate their employees through empowerment (Bass, 1985). Empowerment increases employees' autonomy but reduces their experience of being controlled. Also, through individualized consideration, leaders allow employees greater autonomy over their work (Bass \& Avolio, 1990). Wang and Gagné (2013) demonstrate that TL support self-initiating behaviors in their employees, thus gearing them toward autonomy rather than being controlled. Therefore:

Hypothesis 2c: Employees' perceptions of TL behaviors are negatively related to the employees' controlled motivation.

Finally, amotivated individuals neither value nor feel competent to perform their activities (Ryan \& Deci, 2000b). Rather, they are withdrawn from their task (Meyer \& Gagné, 2008) and are unlikely to be intrinsically or extrinsically motivated (Vallerand \& Blssonnette, 1992). Also, $\mathrm{TL}$ is associated with the motivation and inspiration of employees and they assist employees to perform beyond the employees' self-interest (Avolio, Bass, \& Jung, 1999). They do this by inspiring employees; providing them with meaning and challenge in their work (Stone, Russell, \& Patterson, 2004). The qualities of TL stand in stark contrast to that of amotivation, thus:

Hypothesis 2d: Employees' perceptions of TL behaviors are negatively related to the employees' amotivation.

\section{Employees' motivation and work engagement}

Follower's intrinsic and autonomous motivation and work engagement

We have previously established that followership is complementary to leadership (Agho, 2009) and that followers influence leaders to improve and attain group and organizational goals (Kelley, 1988). Specifically, the followership theory assist researchers and practitioners alike to put the missing link in the leadership literature because it brings more clarity to the understanding of how followers influence leadership behaviors. Therefore, knowledge of the followership theory and the process by which it contributes to the leadership process, competence, and organizational effectiveness (Rosenbach \& Taylor, 2006) is imperative. Parker, Jimmieson, and Amiot (2010) studied job control as a stress buffer when employees type and level of work self-determination is taken into account. They found that when individuals high in self-determination perceived high job control, they experienced greater engagement (in the form of dedication to their work). In addition, when individuals high in non-self-determination perceived high job demands, they experienced more health complaints. On the contrary, our study is concerned with SDM as 
mediators in the relationship between TL perceptions and followers' engagement. More specifically, Parker, Jimmieson, and Amiot (2010) studied SDM as a moderator while we conceptualized motivation as mediators in the TL context.

Kahn (1990) identifies three conditions necessary for engagement: psychological meaningfulness, safety, and availability. We reason that intrinsic and autonomous forms of motivation are key drivers of psychological meaningfulness at work. This is because individuals who possess job autonomy also experience job ownership and their actions are not controlled by others (Kiggundu, 1980) promoting meaningfulness. Moreover, employees who experience psychological safety are confident to express themselves within organizational boundaries as they engage their work (Williams, Gagné, Ryan, \& Deci, 2002), while autonomously motivated individuals have volition over their behaviors and actions (Deci \& Ryan, 1985a) and are more likely to be psychologically available in their work. Parker, Jimmieson, and Amiot (2010) found that individual types of motivation from a self-determination perspective explain the additional variance in employees' strain and engagement, while those who experienced self-determined work motivation also possessed an energizing force that acted as a stress buffer. The above suggests that intrinsically and autonomously motivated employees are likely to be more engaged in their work. Thus:

Hypothesis 3a: Employees' intrinsic motivation is positively related to the employees' work engagement.

Hypothesis 3b: Employees' autonomous motivation is positively related to the employees' work engagement.

\section{Employees' controlled motivation and work engagement}

We speculate that employees with controlled motivation are unlikely to experience work engagement because they perform their tasks for contingent rewards or punishment (Gagne \& Deci, 2005; Ryan \& Deci, 2000a). Also, individuals who experience contingent rewards and punishments may suffer feelings of pressure and conflict originating from the need to behave in a certain manner in order to preserve their egos (Ryan, 1982), and these may trigger stress (Deci \& Ryan, 2000; Lepine, Podsakoff, \& Lepine, 2005) and burnout (Schaufeli et al., 2002) that are oppose to work engagement. Ultimately, stress is incompatible with psychological safety and subsequent work engagement. Thus:

Hypothesis 3c: Controlled motivation is negatively related to the employees' work engagement.

\section{Employees' amotivation and work engagement}

Finally, amotivation is the state of lacking intentions to act (Ryan \& Deci, 2000a) and involves the feelings of incompetence and lack of control (Pelletier, Dion, Slovinec-D'Angelo, \& Reid, 2004), that may trigger helplessness and stress (Basford, Offermann, \& Wirtz, 2012). Ratelle Guay, Vallerand, Larose, and Senécal (2007) show that amotivated individuals feel a lack of motivation and do not perceive the contingencies between their actions and consequences. Thus, we hypothesize that:

Hypothesis 3d: Amotivation is negatively related to the employees' work engagement.

\section{Employees' motivation as a mediator in the relationship between employees' perceptions of TL and work engagement}

Research related to SDT emphasize the importance of examining the different forms of motivation as are differentially linked with affective, attitudinal, and behavioral outcomes (Gagne \& Deci, 2005; see also Fernet, Trépanier, Austin, Gagné, \& Forest, 2015). There is evidence that 
autonomous motivation is related to employee outcomes (Fernet, 2013), however, only autonomous motivation and controlled motivation were examined in this study. Studies investigating the simultaneous implications of the full range of SDM on work engagement are still rare (Fernet, 2013).

We contend that an element of individual decision-making is connected with work engagement and thus we reason that the employees' SDM is a key driver in this process. SDT postulates that in order to be involved in work engagement, employees need to feel competent, related, and autonomous (Deci \& Ryan, 2000). In this regard and while employees are predicted to experience higher levels of autonomy when they perceive TL behaviors, these perceptions are a cognitive process and are internal to the follower (Carsten et al., 2010). This suggests that the regulation of events that influence motivational autonomy also occurs within the individual. Therefore, the extent of employees' internalization of values and the alignment of their values with those of their leader may explain the degree and types of motivation experienced by employees.

Furthermore, Kovjanic and colleagues (2012) show that the followers' need for autonomy mediated the link between TL (not followers' perceptions of TL). Also, Ntoumanis (2001) demonstrates in a study with SEM analysis that intrinsic motivation was related to positive consequences, while external regulation (i.e., controlled motivation ) and amotivation are connected with negative consequences. We argue that the extent of employees' work engagement may also be explained by the types and degree of motivation activated in the follower given TL behaviors. Thus:

Hypothesis 4: Employees' motivation (intrinsic, autonomous, controlled, amotivation) mediates the relationship between the employees' perceptions of their leaders' TL behaviors and the employees' work engagement such that the relationship between followers perceptions of TL and work engagement is strongest for intrinsic and autonomous but weakest for controlled and amotivation.

\section{Methods}

\section{Sample and procedure}

After ethical clearance, we collected data from 180 individuals working in finance and event management organization in Singapore. Data were collected using QUALTRICS and respondents had no remuneration for participation. Only participants who had a specific leader were invited to complete the survey. While it is not uncommon for researchers to assess TL and followers' behaviors using self-reports (e.g., TL behaviors to be measured by followers; see Aw \& Ayoko, 2017; Dung \& Sosik, 2004), the point of departure is that the current research is mainly concerned with followers' perceptions of TL and not TL behaviors in themselves. In this respect, we reason that the most appropriate data will be those collected from the followers of TL and not from the TL themselves. Given the above, we asked the participants to answer demographic questions and then rate the transformational behaviors of their leader. Two weeks after, participants completed a questionnaire on their motivation and engagement. Participants got their links to the Qualtrics portal through e-mail.

\section{Measures}

Multifactor Leadership Questionnaire (MLQ)

We employed the MLQ (MLQ5X; Avolio \& Bass, 1995) with 25 items to measure employees' perceptions of their leaders' transformational behaviors. Representative item on MLQ scales ( $\alpha$ 0.94) includes 'My leader envisions exciting new possibilities' rated on a seven-point Likerttype scale with anchors from 'Not at all' to 'Always.' 
Table 1. Descriptive statistics and intercorrelations of variables used in the study

\begin{tabular}{|c|c|c|c|c|c|c|c|c|c|c|c|c|}
\hline Variables & $\mathrm{n}$ & Mean & $S D$ & 1 & 2 & 3 & 4 & 5 & 6 & 7 & 8 & 9 \\
\hline 1. Age & 155 & 1.560 & 0.498 & & & & & & & & & \\
\hline 2. Gender & 155 & 2.460 & 2.121 & 0.114 & & & & & & & & \\
\hline 3. Education & 155 & 3.990 & 1.741 & 0.131 & 0.102 & & & & & & & \\
\hline 4. Perceptions of TL & 155 & 4.580 & 1.227 & $0.197^{\star}$ & -.055 & .022 & $\alpha=0.97$ & & & & & \\
\hline 5. Intrinsic motivation & 155 & 4.613 & 1.309 & .063 & -0.053 & $0.217^{\star *}$ & $0.319^{* *}$ & $\alpha=0.83$ & & & & \\
\hline 6. Autonomous motivation & 155 & 4.369 & 1.308 & $0.184^{\star}$ & -0.096 & $0.198^{\star}$ & $0.433^{\star *}$ & $0.757^{\star \star}$ & $\alpha=0.88$ & & & \\
\hline 7. Controlled motivation & 155 & 4.477 & 1.233 & -0.056 & -0.127 & 0.062 & $0.227^{\star \star}$ & $0.649^{\star *}$ & $0.715^{\star \star}$ & $\alpha=0.76$ & & \\
\hline 8. Amotivation & 155 & 2.723 & 1.257 & -0.137 & -0.158 & $-0.176^{\star}$ & -0.009 & -0.035 & 0.074 & $0.167^{*}$ & $\alpha=0.72$ & \\
\hline 9. Work engagement & 155 & 4.671 & 1.379 & $0.323^{\star *}$ & 0.009 & $0.289^{\star \star}$ & $0.429^{\star *}$ & $0.575^{\star *}$ & $0.555^{\star \star}$ & $0.272^{\star \star}$ & $-0.242^{\star \star}$ & $\alpha=0.94$ \\
\hline
\end{tabular}

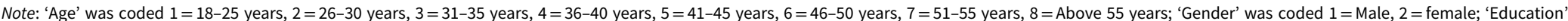

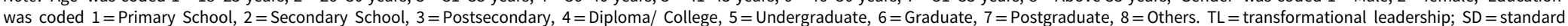
deviation. ${ }^{*}$ Correlation is significant at the .05 level (2-tailed); ${ }^{*}$ Correlation is significant at the .01 level (2-tailed). 
The work extrinsic intrinsic motivation scale (WEIMS)

The WEIMS (Tremblay et al., 2009) was employed to measure employees' individual levels and types of motivation. WEIMS ( $\alpha=0.60$ to 0.84$)$ consist of items that measure the various dimensions of SDT such as 'I derive much pleasure from learning new things.' Items were rated on a seven-point Likert-type scale with anchors from 'Does not correspond at all' to 'Corresponds exactly.'

\section{Individual work engagement}

We measured individual work engagement using the 9-item version $(\alpha 0.92)$ of the Utrecht Work Engagement Scale (UWES; Schaufeli, Bakker, \& Salanova, 2006) that includes 'At work, I feel bursting with energy' and rated on anchors from 'Never' to 'Everyday.' To reduce common method bias, we collected data on the variables of employees' perceptions of TL and about 2 weeks later collected data on employees' individual motivation and engagement.

\section{Demographics and personalities}

Based on the work of Komarraju and Karau (2005), we include employees' gender, age, and education level as control measures. Also, we administered an adapted Mini International Personality Item Pool (Mini IPIP) as a control measure. Individuals rated how accurately the statements describe their personal characteristics in a seven-point Likert-type scale with anchors ranging from 'Very Inaccurate' to 'Very Accurate.'

\section{Data analysis and results}

\section{Data preparation and screening}

Reponses from only 155 participants were usable. This total sample consisted of 68 males (43.9\%) and 87 females $(56.1 \%)$ in the range of $18-25$ years. The qualifications of the sample were secondary education (31.6\%), undergraduates (21.9\%), diploma/'A'-level certificate holders (19.4\%), and graduate (16.8\%).

\section{Construct validation and reliability tests}

We performed confirmatory factor analysis (CFA) using AMOS 21. Due to the low factor loading (below 0.50), two items ('my leader sets high standards' and 'my leader questions the traditional way of doing things') were removed from the 25 -item TL scale to get a model fit [comparative fit index $(\mathrm{CFI})=0.87$, tucker lewis index $(\mathrm{TLI})=0.86$ and root mean square error of approximation $($ RMSEA $)=0.11](\alpha=0.97)$. A slightly lower fit index is not uncommon (see Mitchell \& Ambrose, 2007; Van Dierendonck, 2004). We followed the above studies to proceed with data analysis.

The model fit for WEIMS was improved by removing two items with poor factor loading ('For the income it provides me' and 'Because it allows me to earn money') resulting in a model fit $(\mathrm{CFI}=0.87$; $\mathrm{TLI}=0.84$; $\mathrm{RMSEA}=0.11)$. Given that we were interested in the impact of employees' perceptions of TL on various dimensions of motivation, we adopted the four-factor approach to SDT (Judge, Bono, Erez, \& Locke, 2005) with the following reliability scores: intrinsic motivation (INTR), $\alpha=0.83$; autonomous motivation (AUTO), $\alpha=0.88$; controlled motivation (CONT), $\alpha=0.76$; amotivation (AMOT), $\alpha=0.72$.

One item in the work engagement scale: 'I get carried away when I am working' was removed from the CFA model as it was loading poorly. The results of the CFA for the work engagement scale were $\mathrm{CFI}=0.84$, TLI $=0.79$, and $\mathrm{RMSEA}=0.24$, showing the best model fit with a reliability score of $\alpha=0.94$.

\section{Hypotheses testing}

Table 1 presents the means, standard deviations, reliabilities, and correlations of the variables used in the present study. The intercorrelations between the three motivation constructs were 
Table 2. Regression results ( $T L$ on WE)

\begin{tabular}{|c|c|c|c|c|c|c|}
\hline & Coefficient & $S E$ & $t$ & $p$ & $\mathrm{LLCl}$ & ULCI \\
\hline Constant & 1.6555 & 0.5057 & 3.2740 & .0013 & 0.6564 & 2.6547 \\
\hline Transformational leadership & 0.4218 & 0.0774 & 5.4496 & .0000 & 0.2688 & 0.5747 \\
\hline \multicolumn{7}{|c|}{ Effect of controls on DV } \\
\hline Age & 0.1397 & 0.0453 & 3.0822 & .0024 & 0.0501 & 0.2292 \\
\hline Gender & -0.0566 & 0.1890 & -0.2998 & .7648 & -0.4300 & 0.3167 \\
\hline Education & 0.1996 & 0.0540 & 3.6989 & .0003 & 0.0930 & 0.3062 \\
\hline
\end{tabular}

Note: $N=155$. $D V=$ work engagement.; $T L=$ transformational leadership; $L L C l=$ lower limit confidence interval; ULCl=upper limit confidence interval; $\mathrm{SE}=$ standard error.

higher than 0.60 because each variable is measuring different qualities of the single higher order variable of motivation (Ratelle et al., 2007). However, their reliability scores were in the acceptable range (above 0.70 ). The VIF scores for the variables were less than 2.4 and given that the reliability scores were higher than 0.70 for the variables; we concluded that multicollinearity does not pose a problem (Grewal, Cote, \& Baumgartner, 2004). Furthermore, we employed Hayes (2013) 'PROCESS' macros (model 4) to run regression models to test the hypothesized links on our conceptual model (see Figure 1). By applying the bootstrapped confidence intervals (CIs), the problems associated with asymmetric and other nonnormal sampling distributions of an indirect effect are avoided (Preacher \& Hayes, 2008). The variables of personality, age, gender, and education were imputed as covariates in the model and the regression analysis was performed using 10,000 bootstraps.

Hypothesis 1 predicted that employees' perceptions of their leaders' TL behavior would be positively related to the employees' work engagement. The control variables of age $(B=0.14$; $t=3.1 ; p<0.01)$ and education $(B=0.20 ; t=3.70 ; p<0.001)$ were significant in this model (see Table 2). Also, the exclusion of zero value in the bias-corrected CIs indicated a significant association of follower's perceptions of TL and employees' work engagement $(B=0.42 ; t=5.45$; $p<0.001)$. Hence, Hypothesis 1 is accepted.

Hypothesis 2a predicted that employees' perceptions of TL would be positively related to employees' intrinsic motivation. As the bias-corrected bootstrap CIs excluded zero, both education $(B=0.16 ; t=2.87 ; p<0.05)$ and the link between perceptions of TL and employees' individual levels of intrinsic motivation were significant $(B=0.34 ; t=4.09 ; p<0.01$; see Table 3), supporting Hypothesis $2 \mathrm{a}$. Hypothesis $2 \mathrm{~b}$ predicted that perceptions of TL would be positively linked to employees' level of autonomous motivation. Education $(B=0.14 ; t=2.60$; $p<0.05)$ and higher levels of perceptions of TL were related to higher levels of autonomous motivation $(B=0.43 ; t=5.56 ; p<0.001$; see Table 4$)$, supporting Hypothesis $2 \mathrm{~b}$. In Hypothesis $2 c$, we predicted that the follower's perception of TL would be negatively related to the follower's level of controlled motivation. Surprisingly, employees who perceived high levels of TL behaviors also reported higher levels of controlled motivation $(B=0.24 ; t=2.99 ; p<0.01$; see Table 5), disconfirming Hypothesis $2 \mathrm{c}$. Hypothesis $2 \mathrm{~d}$ predicted that the employees' perceptions of leaders' TL behaviors would be negatively related to the employees' level of amotivation. Results (see Table 6) showed no significant relationship between employees' perceptions of the leaders' TL behaviors and employees' amotivation. Besides, there was a zero value between the bias-corrected bootstrap CIs disconfirming Hypothesis $2 \mathrm{~d}$.

Hypothesis 3a predicted that the employees' intrinsic motivation would be positively related to work engagement. Age $(B=0.10 ; t=2.66 ; p<0.01)$ and employees' higher levels of intrinsic motivation were linked with higher levels of work engagement $(B=0.41 ; t=4.24 ; p<0.001$; see Table 7), confirming Hypothesis $3 \mathrm{a}$. Also, given that the bias-corrected bootstrap CIs excluded 
Table 3. Model summary (TL on INTR)

\begin{tabular}{|c|c|c|c|c|c|c|}
\hline$R^{2}$ & $F$ & \multicolumn{2}{|c|}{$d f 1$} & \multicolumn{2}{|c|}{$d f 2$} & $p$ \\
\hline 0.3867 & 6.5939 & \multicolumn{2}{|c|}{4.0000} & \multicolumn{2}{|c|}{150.0000} & 0.0001 \\
\hline \multicolumn{7}{|l|}{ Regression results (TL on INTR) } \\
\hline & Coefficient & SE & $t$ & $p$ & $\mathrm{LLCl}$ & ULCI \\
\hline Constant & 2.6773 & 0.5371 & 4.9850 & .0000 & 1.6161 & 3.7385 \\
\hline Transformational leadership & 0.3361 & 0.0822 & 4.0892 & .0001 & 0.1737 & 0.4986 \\
\hline \multicolumn{7}{|c|}{ Effect of controls on DV } \\
\hline Age & -0.0134 & 0.0481 & -0.2774 & .4676 & -0.1085 & 0.0818 \\
\hline Gender & -0.1462 & 0.2007 & -0.7283 & .7818 & -0.5427 & 0.2504 \\
\hline Education & 0.1646 & 0.0573 & 2.8713 & .0047 & 0.0513 & 0.2778 \\
\hline
\end{tabular}

Note: $N=155$. DV = Intrinsic motivation; $\mathrm{TL}=$ transformational leadership; $\mathrm{LLCl}=$ lower limit confidence interval; ULCI=upper limit confidence interval; $\mathrm{SE}=$ standard error; INTR = intrinsic.

zero, our results revealed that employees who reported higher levels of autonomous motivation $(B=0.29 ; t=2.54 ; p<0.05)$ also reported higher levels of work engagement. Hypothesis $3 \mathrm{~b}$ is accepted. Moreover, results showed employees' controlled motivation was negatively linked with work engagement $(B=-0.21 ; t=-2.14 ; p<0.05)$, supporting Hypothesis $3 c$. Additionally, individuals who were amotivated $(B=-0.19 ; t=-2.92 ; \mathrm{p}<0.01)$ displayed lower levels of work engagement, supporting Hypothesis $3 \mathrm{~d}$. Altogether, our results confirm that both intrinsic and autonomous motivations are positively related to work engagement, while controlled motivation and amotivation negatively impact engagement.

In Hypothesis 4, we predicted that employees' motivation would mediate the relationship between employees' perceptions of TL's behavior and their work engagement. The regression outputs provide the bootstrap confidence intervals (99 and 95\%), but our focus is on the 95th percentile. The aim was to see whether the zero value would be within the interval range, that is, within the lower limit (LL) and the upper limit (UL). By examining the interval range, we are interested in finding out whether, there will be a true indirect effect of zero with $95 \%$ confidence, suggesting no mediation. In this regard, if zero value does not occur between LL and UL values, then we can conclude that the indirect effect is significant. Using the above guide, the regression results of the mediation, both the direct effect (effect: 0.2144; Boot LLCI: 0.0736; Boot ULCI: 0.3552) and the indirect effect (effect: 0.2073; Boot LLCI: 0.1180; Boot ULCI: 0.4293 ) of perceptions of TL on work engagement, were significant. The results revealed that both intrinsic motivation (effect: 0.1361; Boot LLCI: 0.0606; Boot ULCI: 0.2655) and autonomous motivation (effect: 0.1231; Boot LLCI: 0.0378; Boot ULCI: 0.2331) mediated the relationship between employees' perceptions of TL behavior and work engagement, suggesting that employees' SDM (intrinsic and autonomous) is important in explaining how the employees' perceptions of TL may increase their work engagement. Furthermore, controlled motivation had a negative mediating effect (effect $=-0.0503$; Boot LLCI $=-0.1295$; Boot $\mathrm{ULCI}=-0.0053)$ in the relationship between employees' perceptions of TL and employees' work engagement (see Table 7), while amotivation did not significantly contribute to the mediating effects of SDM in the link between employees' perception of TL behaviors and work engagement. 
Table 4. Model summary (TL on AUTO)

\begin{tabular}{|c|c|c|c|c|c|c|}
\hline$R^{2}$ & $F$ & \multicolumn{2}{|c|}{$d f 1$} & \multicolumn{2}{|c|}{$d f 2$} & $p$ \\
\hline 0.2392 & 11.7900 & \multicolumn{2}{|c|}{4.0000} & \multicolumn{2}{|c|}{150.0000} & .0000 \\
\hline \multicolumn{7}{|l|}{ Regression results (TL on AUTO) } \\
\hline & Coefficient & $S E$ & $t$ & $p$ & LLCI & ULCI \\
\hline Constant & 2.1117 & 0.5076 & 4.1601 & .0001 & 1.1087 & 3.1147 \\
\hline Transformational leadership & 0.4319 & 0.0777 & 5.5590 & .0000 & 0.2784 & 0.5854 \\
\hline \multicolumn{7}{|c|}{ Effect of controls on DV } \\
\hline Age & 0.0566 & 0.0455 & 1.2432 & .2157 & -0.0333 & 0.1465 \\
\hline Gender & -0.2706 & 0.1897 & -1.4265 & .1558 & -0.6454 & 0.1042 \\
\hline Education & 0.1408 & 0.0542 & 2.5987 & .0103 & 0.0337 & 0.2478 \\
\hline
\end{tabular}

Note: $N=155$. DV = intrinsic motivation; $\mathrm{TL}=$ transformational leadership; $\mathrm{LLCl}=$ lower limit confidence interval; $\mathrm{ULCl}=$ upper limit confidence interval; $\mathrm{SE}=$ standard error; $\mathrm{AUTO}=$ autonomous.

\section{Discussion and conclusion}

We proposed and tested a model of how employees' perceptions of their TL's behaviors may activate forms of SDM and the mediating effects of such types of motivation on employees' work engagement. We found that higher levels of perceived TL was associated with high levels of work engagement. Although Tims, Bakker, and Xanthopoulou (2011) found a positive relationship between TL and work engagement, other studies (e.g., Christian, Garza, \& Slaughter, 2011) found the relationship between TL and work engagement to be insignificant, suggesting mixed findings. Our results showed that even for employees, the perceptions of TL improved their work engagement. More research is needed to examine other potential conditions for employees' engagement in the presence of TL.

Our results showed that employees who perceived TL behaviors also reported higher levels of intrinsic motivation. Shamir and colleagues propose that TL is related to subjective perceptions of the employees and is able to increase employees' intrinsic motivation. Our results are one of the first few to confirm this proposition. Additionally, Bono and Judge (2003) argue that subordinates of transformational leaders may be more likely to choose more autonomous and intrinsic goals. We found that employees' perceptions of TL were positively connected with individual's autonomous motivation. By communicating attractive goals using universalistic values (Bass, 1985), transformational leaders may be able to influence their employees to attain a congruent perception of the goals set for them with their personal values (Bono \& Judge, 2003), thereby allowing employees to become autonomously driven to pursue them (Gagne \& Deci, 2005). Besides, employees who perceived higher levels of leaders' transformational behaviors also reported higher levels of controlled motivation. TL behaviors involve granting employees some autonomy and empowerment to make decisions (Bass, 1985; Bass \& Avolio, 1990). Perhaps, higher levels of autonomy provided by TL may reduce the feelings of being controlled.

The results of our prediction of a negative link between employees' perceptions of the leaders' TL behaviors and amotivation were nonsignificant. Existing studies showed that amotivated individuals are usually withdrawn (Meyer \& Gagné, 2008) and do not regulate their actions based on any external situation or circumstance (Ryan, 1995). Future research should continue to isolate the specific context(s) for amotivation while determining the possible actions that leaders could take to reduce amotivation. 
Table 5. Model summary (TL on CONT)

\begin{tabular}{|c|c|c|c|c|c|c|c|}
\hline$R$ & $R^{2}$ & $F$ & \multicolumn{2}{|c|}{$d f 1$} & \multicolumn{2}{|c|}{$d f 2$} & $p$ \\
\hline 0.2817 & 0.0793 & 3.2312 & \multicolumn{2}{|c|}{4.0000} & \multicolumn{2}{|c|}{150.0000} & .0141 \\
\hline \multicolumn{8}{|c|}{ Regression results (TL on CONT) } \\
\hline & & Coefficient & SE & $t$ & $p$ & LLCI & ULCI \\
\hline Constant & & 3.7194 & 0.5263 & 7.0675 & .0000 & 2.6795 & 4.7592 \\
\hline Transformational Leadership & & 0.2407 & 0.0805 & 2.9883 & .0033 & 0.0815 & 0.3999 \\
\hline \multicolumn{8}{|c|}{ Effect of controls on DV } \\
\hline Age & & -0.0590 & 0.0472 & -1.2502 & .2132 & -0.1522 & 0.0342 \\
\hline Gender & & -0.2747 & 0.1967 & -1.3966 & .1646 & -0.6632 & 0.1139 \\
\hline Education & & 0.0575 & 0.0562 & 1.0246 & .3072 & -0.0534 & 0.1685 \\
\hline
\end{tabular}

Note: $N=155$. DV = intrinsic motivation; $\mathrm{TL}=$ transformational leadership; $\mathrm{LLCl}=$ lower limit confidence interval; $\mathrm{ULCl}=$ upper limit confidence interval; $\mathrm{SE}=$ standard error; $\mathrm{CONT}=$ controlled.

Both intrinsic and autonomous types of motivation were related to higher levels of work engagement in our study. Parker, Jimmieson, and Amiot (2010) found a positive relationship between self-determination, perceived job control and engagement (in the form of dedication to their work); while when individuals high in nonself-determination perceived high job demands, they experienced more health complaints. Their results suggest that self-determination is linked with engagement. In this regard, our results are consistent with Parker, Jimmieson, and Amiot (2010) . Nevertheless, these authors adopted SDT as a moderator in their examination of job demands and strain affecting individuals' work engagement. Our results go beyond those of Parker, Jimmieson, and Amiot (2010) to extend literature by examining the direct impact of employees' SDM on their own work engagement using SDT as a theoretical anchor. The current study is also one of the first few to establish a link between controlled motivation and work engagement. Surprisingly we found that the employees' perceptions of TL are linked with controlled motivation. There are suggestions that the pressure associated with controlled motivation may reduce the employees' experience of psychological safety and availability (Lepine et al., 2005). Our results validate these propositions. Also, the current findings reiterate earlier results that amotivation is negatively related to work engagement. Amotivated individuals are known to lack intentions to perform their job (Ryan \& Deci, 2000a), tend to feel incompetent and helpless (Pelletier et al., 2004), and are not likely to psychologically engage their work (Kahn, 1990).

Moreover, we found that motivation (intrinsic, autonomous, and controlled) successfully mediated the link between employees' perceptions of TL and work engagement. Interestingly, by negatively mediating the relationship between employees' perceptions of TL and work engagement, controlled motivation reduced the effect of employees' TL perceptions on work engagement (Castro \& Matute, 2010). Finally, it is not surprising that amotivation was not a successful mediator. Vallerand and Blssonnette (1992) showed that people who are amotivated are neither intrinsically nor extrinsically motivated and are associated with negative consequences (Vallerand, 2000). More research is needed on how leaders can reduce amotivation at work. Overall, the partial mediation established in this model confirms that employees' motivation may explain the link between employees' perceptions of TL behaviors and work engagement.

Our study makes three significant theoretical contributions. First, the current research departs from extant literature by examining the impact of employees' perceptions of TL on follower motivation and engagement. Our results demonstrate the connection between employees' 
Table 6. Model summary (TL on AMOT)

\begin{tabular}{|c|c|c|c|c|c|c|c|}
\hline$R$ & $R^{2}$ & $F$ & \multicolumn{2}{|c|}{$d f 1$} & \multicolumn{2}{|c|}{$d f 2$} & $p$ \\
\hline 0.2469 & 0.0610 & 2.4350 & \multicolumn{2}{|c|}{4.0000} & \multicolumn{2}{|c|}{150.0000} & 0.0498 \\
\hline \multicolumn{8}{|c|}{ Regression results (TL on AMOT) } \\
\hline & & Coefficient & $S E$ & $t$ & $p$ & LLCI & ULCI \\
\hline Constant & & 3.7817 & 0.5421 & 6.9757 & .0000 & 2.7105 & 4.8529 \\
\hline Transformational Leadership & & 0.0080 & 0.0830 & 0.0961 & .9236 & -0.1560 & 0.1719 \\
\hline \multicolumn{8}{|c|}{ Effect of controls on DV } \\
\hline Age & & -0.0619 & 0.0486 & -1.2737 & .2047 & -0.1579 & 0.0341 \\
\hline Gender & & -0.3287 & 0.2026 & -1.6226 & .1068 & -0.7290 & 0.0716 \\
\hline Education & & -0.1076 & 0.0579 & -1.8605 & .0648 & -0.2220 & 0.0067 \\
\hline
\end{tabular}

Note: $N=155$. $\mathrm{DV}=$ intrinsic motivation; $\mathrm{TL}=$ transformational leadership; $\mathrm{LLCl}=$ lower limit confidence interval; $\mathrm{ULCl}=\mathrm{upper}$ limit confidence interval; $\mathrm{SE}=$ standard error; $\mathrm{AMOT}=$ amotivation.

perceptions of TL and work engagement, thus demonstrating that employees (e.g., perceptions) matter in the leadership process. Altogether, we contribute to TL, employees, and engagement literature. Second, we extend the SDM literature (see Benedetti, Diefendorff, Gabriel, \& Chandler, 2015; Moran, Diefendorff, Kim, \& Liu, 2012) by using SDT as a launch pad to examine the hypothesized variables. To our knowledge, the current study is the first to examine the impact of the employees' perceptions of TL on self-determination motivation and work engagement using SDT as a theoretical frame (see Macey \& Schneider, 2008). Third, by establishing the presence of the mediating effects of dimensions of SDM between TL and work engagement, the current research extends literature in this area (Brown \& Dant, 2008).

By demonstrating that employees' perceptions of their TL behaviors are related to SDM, training in TL is implicated. Barling, Weber, and Kelloway (1996) show that training in TL boosted subordinates perception of TL, commitment to organization, and financial performance. Training activities in TL should include leaders' ability to recognize the employees and organizational contextual (Groves \& LaRocca, 2011) characteristics. Avolio (2007) argues that employees' characteristics (e.g., experience, cultural orientation and social/physical distance) may have a role to play in the employees' perceptions of their leaders. Besides Lord, Brown, Harvey, and Hall (2001) advocate that perceptions of leaders are grounded within larger social, cultural, task, and interpersonal environment and thus, leaders should take cognizance of the environment or climate of the organization to improve the employees' perceptions of their leaders' behaviors. Similarly, the training package should pay attention to enhancing employees' motivation (intrinsic and autonomous). Specifically, the design of the training package should be based on a survey of what employees consider important for promoting their intrinsic or autonomous motivation. For example, the training in this area should include exercises that can promote curiosity and meaningful challenge that may promote high levels of self-esteem where goals that are set have rewards attached to them. Managers should also create a safe and blamefree environment (Kark, Shamir, \& Chen, 2003) and an opportunity to have a control over what they do, to foster an environment conducive for triggering employees' experience of motivational autonomy.

The present research presents some limitations. While we established that employees' perceptions of leadership impact their engagement, there is a possibility that other factors (e.g., perceived organizational support, organizational culture) may explain how perceptions of TL 
Table 7. Overall model summary (TL, INTR, AUTO, CONT and AMOT on WE)

\begin{tabular}{|c|c|c|c|c|c|c|}
\hline$R^{2}$ & $F$ & \multicolumn{2}{|c|}{$d f 1$} & \multicolumn{2}{|c|}{$d f 2$} & $p$ \\
\hline 0.5322 & 20.7642 & \multicolumn{2}{|c|}{8.0000} & \multicolumn{2}{|c|}{146.0000} & 0.0000 \\
\hline \multicolumn{7}{|c|}{ Overall regression results (TL, INTR, AUTO, CONT, and AMOT on WE) } \\
\hline & Coefficient & $S E$ & $t$ & $p$ & $\mathrm{LLCl}$ & ULCI \\
\hline Constant & 1.4693 & 0.5362 & 2.7402 & .0069 & 0.4096 & 2.5290 \\
\hline Intrinsic motivation & 0.4050 & 0.0955 & 4.2392 & .000 & 0.2162 & 0.5938 \\
\hline Autonomous motivation & 0.2850 & 0.1123 & 2.5369 & .0122 & 0.0630 & 0.5070 \\
\hline Controlled motivation & -0.2092 & 0.0978 & -2.1384 & .0341 & -0.4025 & -0.0158 \\
\hline Amotivation & -0.1909 & 0.0652 & -2.9278 & .0040 & -0.3197 & -0.0620 \\
\hline Transformational Leadership & 0.2144 & 0.0712 & 3.0101 & .0031 & 0.0736 & 0.3352 \\
\hline \multicolumn{7}{|c|}{ Effect of controls on DV } \\
\hline Age & 0.1048 & 0.0394 & 2.6597 & .0087 & 0.0269 & 0.1827 \\
\hline Gender & -0.0405 & 0.1596 & -0.2540 & .7999 & -0.3559 & 0.2748 \\
\hline Education & 0.0843 & 0.0471 & 1.7919 & .0752 & -0.0087 & 0.1773 \\
\hline \multicolumn{7}{|l|}{ Summary of total effects } \\
\hline & Effect & $S E$ & $t$ & $p$ & $\mathrm{LLCl}$ & ULCI \\
\hline Total effect of TL on WE & 0.4218 & 0.0774 & 5.4496 & .0000 & 0.2688 & 0.5747 \\
\hline \multirow[t]{2}{*}{ Direct effect of TL on WE } & 0.2144 & 0.0712 & 3.0101 & .0031 & 0.0736 & 0.3552 \\
\hline & Effect & Boot $S E$ & & & Boot LLCI & Boot ULCI \\
\hline Total indirect effect & 0.2073 & 0.0523 & & & 0.1180 & 0.3293 \\
\hline Intrinsic motivation & 0.1361 & 0.0497 & & & 0.0606 & 0.2655 \\
\hline Autonomous motivation & 0.1231 & 0.0479 & & & 0.0378 & 0.2331 \\
\hline Controlled motivation & -0.0503 & 0.0297 & & & -0.1295 & -0.0053 \\
\hline Amotivation & -0.0015 & 0.0165 & & & -0.0360 & 0.0289 \\
\hline \multicolumn{7}{|c|}{ Specific indirect effect contrasts } \\
\hline (INTR-AUTO) & 0.0131 & 0.0743 & & & -0.1067 & 0.1741 \\
\hline (INTR-CONT) & 0.1865 & 0.0661 & & & 0.0769 & 0.3392 \\
\hline (INTR-AMOT) & 0.1377 & 0.0501 & & & 0.0562 & 0.2588 \\
\hline (AUTO-CONT) & 0.1734 & 0.0677 & & & 0.0538 & 0.3182 \\
\hline (AUTO-AMOT) & 0.1246 & 0.0536 & & & 0.0326 & 0.2425 \\
\hline (CONT-AMOT) & -0.0488 & 0.0331 & & & -0.1340 & 0.0059 \\
\hline
\end{tabular}

Note: $N=155$. IV = TL; DV = WE; M = INTR, AUTO, CONT, AMOT DV= work engagement; $T L=$ transformational leadership; $L L C l=$ lower limit confidence interval; $\mathrm{ULCl}=$ upper limit confidence interval; $\mathrm{SE}=$ standard error; $\mathrm{AMOT}=$ amotivation; $\mathrm{AUTO}=$ autonomous; $\mathrm{CONT}=$ controlled; INTR = intrinsic. 
behaviors impact employees' work engagement. Altogether, our results should be interpreted and generalized with caution. Future research should examine the impact of industry, culture, and other factors that may impact the variables studied in this research. Additionally, the study is cross-sectional and the results from CFAs for each of the individual constructs used in the present research could have a better model fit. Nevertheless, the use of near perfect model fits is not new (Van Dierendonck, 2004). We suspect that our reported model fit issues may also be a function of our young and small sample size. However, we employed bootstrapping method (Hayes macros) known for its suitability for analyzing small samples. Despite this limitation, the majority of hypothesized relationships between the variables on our model were statistically significant. Future research should use larger, mature age samples and a longitudinal approach to track the influence of the employees' perceptions of TL on their work engagement over time. Furthermore, we tested the mediation effect of motivation in the link between employees' perception of TL and engagement. There is a possibility that engagement may also mediate the relationship between employees' perception of TL and motivation. Future research should test the latter to see whether and when engagement may also explain motivation.

Our study has shown that employees' perceptions of TL behaviors positively impact employees' SDM and work engagement while forms of SDM mediate the relationship between employees' perceptions of TL and work engagement. Especially, our study provides an interesting and fresh insight into the link between employees' perceptions of TL and controlled motivation. Altogether, the findings from the present research opens new avenues for future research to adopt SDT as a framework to study the relationship between employees' perceptions of TL, individual motivation, and work engagement.

\section{References}

Agho, A. (2009). Perspectives of senior-level executives on effective followership and leadership. Journal of leadership and Organizational Studies, 16(2), 159-166.

Arnold, K. A., Turner, N., Barling, J., Kelloway, E. K., \& McKee, M. C. (2007). Transformational leadership and psychological well-being: The mediating role of meaningful work. Journal of Occupational Health Psychology, 12(3), $193-203$.

Avolio, B. J., Zhu, W., Koh, W., \& Bhatia, P. (2004). Transformational leadership and organizational commitment: mediating role of psychological empowerment and moderating role of structural distance. Journal of Organizational Behavior, 25(8), 951-968.

Avolio, B. J. (1999). Full leadership development: Building the vital forces in organizations. Thousand Oaks, CA: Sage.

Avolio, B. J. (2007). Promoting more integrative strategies for leadership theory-building. American Psychologist, $62(1), 25$.

Avolio, B. J., \& Bass, B. M. (1995). Individual consideration viewed at multiple levels of analysis: A multi-level framework for examining the diffusion of transformational leadership. The Leadership Quarterly, 6(2), 199-218.

Avolio, B. J., \& Bass, B. M. (2004). MLQ-Multifactor Leadership Quesionnaire. Menlo Park, CA: Mind Garden.

Avolio, B. J., Bass, B. M., \& Jung, D. I. (1999). Reexamining the components of transformational and transactional leadership using the multifactor leadership questionnaire. Journal of Occupational and Organizational Psychology, 72, 441-462.

Aw, V. K. J., \& Ayoko, O. B. (2017). The impact of followers' conflict behaviors on teams' transformational leadership, team member exchange and engagement. International Journal of Conflict Management, 28(4), 509-532. https://doi.org/ 10.1108/IJCMA-04-2016-0020.

Baker, SD (2007). Followership: The theoretical foundation of a contemporary construct. Journal of Leadership \& Organizational Studies, 14(1), 50-60.

Barling, J., Weber, T., \& Kelloway, E. K. (1996). Effects of transformational leadership training on attitudinal and financial outcomes. Journal of Applied Psyhcology, 81(6), 827-832.

Basford, T. E., Offermann, L. R., \& Wirtz, P. W. (2012). Considering the source: The impact of leadership level on follower motivation and intent to stay. Journal of Leadership \& Organizational Studies, 19(2), 202-214.

Bashshur, M. R., Hernández, A., \& González-Romá, V. (2011). When managers and their teams disagree: A longitudinal look at the consequences of differences in perceptions of organizational support. The Journal of Applied Psychology, 96(3), 558-573.

Bass, B. M. (1985). Leadership and performance beyond expectations. New York: Free Press.

Bass, B. M., \& Avolio, B. J. (1990). Developing transformational leadership: 1992 and beyond. Journal of European Industrial Training, 14(5), 21-27. 
Bass, B. M., \& Avolio, B. J. (1994). Improving organizational effectiveness through transformational leadership. Thousand Oaks, CA: Sage.

Bass, B. M., Avolio, B. J., Jung, D. I., \& Berson, Y. (2003). Predicting unit performance by assessing transformational and transactional leadership. Journal of Applied Psychology, 88(2), 207-218.

Benedetti, A. A., Diefendorff, J. M., Gabriel, A. S., \& Chandler, M. M. (2015). The effects of intrinsic and extrinsic sources of motivation on well-being depend on time of day: The moderating effects of workday accumulation. Journal of Vocational Behavior, 88, 38-46.

Bono, J. E., \& Judge, T. A. (2003). Self-concordance at work: Toward understanding the motivational effects of transformational leaders. Academy of Management Journal, 46(5), 554-571.

Brown, J., \& Dant, R. (2008). On what makes a significant contribution to the retailing literature. Journal of Retailing, 84(2), 131-135.

Burns, J. M. (1998). Transactional and transforming leadership. In G. R. Hickman (Ed.), Leading organizations (pp. 133-134). Thousand Oaks, CA: Sage Publications.

Carsten, M. K., Uhl-Bien, M., West, B. J., Patera, J. L., \& McGregor, R. (2010). Exploring social constructions of followership: A qualitative study. The Leadership Quarterly, 21(3), 543-562.

Castro, L., \& Matute, H. (2010). Positive and negative mediation as a function of whether the absent cue was previously associated with the outcome. Quarterly Journal of Experimental Psychology, 63(12), 2359-2375.

Christian, M. S., Garza, A. S., \& Slaughter, J. E. (2011). Work engagement: A quantitative review and test of its relations with task and contextual performance. Personnel Psychology, 64(1), 89-136.

Crossman, B., \& Crossman, J. (2011). Conceptualising followership-A review of the literature. Leadership, 7(4), 481-497.

Conchie, S. M. (2013). Transformational leadership, intrinsic motivation, and trust: A moderated-mediated model of workplace safety. Journal of Occupational Health Psychology, 18(2), 198-210.

Deci, E. L., \& Ryan, R. M. (1985a). Intrinsic motivation and self-determination in human behaviour. New York: Plenum.

Deci, E. L., \& Ryan, R. M. (1985b). The general causality orientations scale: Self-determination in personality. Journal of Research in Personality, 9(2), 109-134.

Deci, E. L., \& Ryan, R. M. (2000). The "what" and "why" of goal pursuits: Human needs and the self-determination of behavior. Psychological Inquiry, 11(4), 227-268.

Dionne, S. D., Yammarino, F. J., Atwater, L. E., \& Spangler, W. D. (2004). Transformational leadership and team performance. Journal of Organizational Change Management, 17(2), 177-193.

Fernet, C. (2013). The role of work motivation in psychological health. Canadian Psychology/Psychologie Canadienne, 54(1), 72.

Felfe, J., \& Schyns, B. (2010). Followers' personality and the perception of transformational leadership: Further evidence for the similarity hypothesis. British Journal of Management, 21, 393-410.

Felfe, S., \& Schyns, B. (2006). Personality and the perception of transformational leadership: The impact of extraversion, neuroticism, personal need for structure, and occupational self-efficacy. Journal of Applied Social Psychology, 36(3), 708-739.

Fernet, C., Trépanier, S. G., Austin, S., Gagné, M., \& Forest, J. (2015). Transformational leadership and optimal functioning at work: On the mediating role of employees' perceived job characteristics and motivation. Work \& Stress, 29(1), 11-31.

Gagne, M., \& Deci, E. L. (2005). Self-determination theory and work motivation. Journal of Organizational Behavior, 26(4), 331-362.

Gagné, M., Forest, J., Gilbert, M., Aubé, C., Morin, E., \& Malorni, A. (2010). The motivation at work scale: Validation evidence in two languages. Educational and Psychological Measurement, 70(4), 628-646.

Grewal, R., Cote, J. A., \& Baumgartner, H. (2004). Multicollinearity and measurement error in structural equation models: Implications for theory testing. Marketing Science, 23(4), 519-529.

Hayes, A. F. (2013). Introduction to mediation, moderation, and conditional process analysis: A regression-based approach. New York: The Guilford Press.

Horsfall, C. (2001). Team leaders make a difference in raising achievement. In C. Horsfall (Ed.), Leadership issues: Raising achievement. London: Learning and Skills Development Agency.

Howell, J. M., \& Shamir, B. (2005). The role of followers in the charismatic leadership process: Relationships and their consequences. Academy of Management Review, 30(1), 96-112.

Hughes, M. L. (1998). Keeping your job while your bosses are losing theirs. New York: William Neil Publishing.

Ilies, R., Judge, T., \& Wagner, D. (2006). Making sense of motivational leadership: The trail from transformational leaders to motivated followers. Journal of Leadership \& Organizational Studies, 13(1), 1-22.

Judge, T. A., Bono, J. E., Erez, A., \& Locke, E. A. (2005). Core self-evaluations and job and life satisfaction: The role of selfconcordance and goal attainment. The Journal of Applied psychology, 90(2), 257-268.

Judge, T. A., \& Piccolo, R. F. (2004). Transformational and transactional leadership: A meta-analytic test of their relative validity. The Journal of Applied Psychology, 89(5), 755-768.

Jung, D., Yammarino, F. J., \& Lee, J. K. (2009). Moderating role of subordinates' attitudes on transformational leadershipand effectiveness: A multi-cultural and multi-level perspective. The Leadership Quarterly, 20, 586-603. 
Kahn, W. A. (1990). Psychological conditions of personal engagement and disengagement at work. Academy of Management Journal, 33(4), 692-724.

Kark, R., Shamir, B., \& Chen, G. (2003). The two faces of transformational leadership: Empowerment and dependency. Journal of Applied Psychology, 88(2), 246-255.

Kelley, R. (1988). In praise of followers. Harvard Business Review, 66(6), 142-148.

Kelley, R. E. (1992). The power of followership: How to create leaders people want to follow, and followers who lead themselves. Broadway Business.

Kelley, R. E. (2008). Rethinking followership. The art of followership: How great followers create great leaders and organizations, 5-16.

Kiggundu, M. N. (1980). An empirical test of the theory of job design using multiple job ratings. Human Relations, 33(5), 339-351.

Komarraju, M., \& Karau, S. J. (2005). The relationship between the big five personality traits and academic motivation. Personality and Individual Differences, 39(3), 557-567.

Kovjanic, S., Schuh, S. C., \& Jonas, K. (2013). Transformational leadership and performance: An experimental investigation of the mediating effects of basic needs satisfaction and work engagement. Journal of Occupational and Organizational Psychology, 86, 543-555.

Kovjanic, S., Schuh, S. C., Jonas, K., van Quaquebeke, N., \& van Dick, R. (2012). How do transformational leaders foster positive employee outcomes? A self-determination-based analysis of employees' needs as mediating links. Journal of Organizational Behavior, 33, 1031-1052.

Küpers, W. (2007). Perspectives on integrating leadership and followership. International Journal of Leadership Studies, 2(3), 194-221.

Lepine, J. A., Podsakoff, N. P., \& Lepine, M. A. (2005). A meta-analytic test of the challenge stressor-hindrance stressor framework: An explanation for inconsistent relationships among stressors and performance. Academy of Management Journal, 48(5), 764-775.

Lord, R. G., Brown, D. J., Harvey, J. L., \& Hall, R. J. (2001). Contextual constraints on prototype generation and their multilevel consequences for leadership perceptions. The Leadership Quarterly, 12(3), 311-338.

Lord, R. G., \& Emrich, C. G. (2000). Thinking outside the box by looking inside the box: Extending the cognitive revolution in leadership research. The Leadership Quarterly, 11(4), 551-579.

Macey, W. H., \& Schneider, B. (2008). The meaning of employee engagement. Industrial and Organizational Psychology, 1 (1), 3-30.

Meyer, J. P., \& Gagné, M. (2008). Employee engagement from a self-determination theory perspective. Industrial and Organizational Psychology, 1(1), 60-62.

Mitchell, M. S., \& Ambrose, M. L. (2007). Abusive supervision and workplace deviance and the moderating effects of negative reciprocity beliefs. Journal of Applied Psychology, 92(4), 1159.

Moran, C. M., Diefendorff, J. M., Kim, T., \& Liu, Z. (2012). A profile approach to self-determination theory motivations at work. Journal of Vocational Behavior, 81, 354-363.

Ntoumanis, N. (2001). A self-determination approach to the understanding of motivation in physical education. British Journal of Educational Psychology, 71(2), 225-242.

Nübold, A., Muck, P. M., \& Maier, G. W. (2013). A new substitute for leadership ? Followers' state core self-evaluations. The Leadership Quarterly, 24(1), 29-44.

Parker, S. L., Jimmieson, N. L., \& Amiot, C. E. (2010). Self-determination as a moderator of demands and control: Implications for employee strain and engagement. Journal of Vocational Behavior, 76(1), 52-67.

Pelletier, L. G., Dion, S. C., Slovinec-D’Angelo, M., \& Reid, R. (2004). Why do you regulate what you eat? Relationships between forms of regulation, eating behaviors, sustained dietary behavior change, and psychological adjustment. Motivation and Emotion, 28(3), 245-277.

Piccolo, R. F., \& Colquitt, J. A. (2006). Transformational leadership and job behaviors: The mediating role of core job characteristics. Academy of Management Journal, 49(2), 327-340.

Pinder, C. C. (1998). Work motivation in organizational behavior. Saddle River, NJ: Prentice Hall.

Ratelle, C. F., Guay, F., Vallerand, R. J., Larose, S., \& Senécal, C. (2007). Autonomous, controlled, and amotivated types of academic motivation: A person-oriented analysis. Journal of Educational Psychology, 99(4), 734-746.

Riggio, R. E., Chaleff, I., \& Lipman-Blumen, J. (Eds.), (2008). The art of followership: How great followers create great leaders and organizations (Vol. 146). John Wiley \& Sons.

Rosenbach, W., \& Taylor, R. (2006). Contemporary issues in leadership. Boulder, CO: Westview Press.

Ryan, R. M. (1995). Psychological needs and the facilitation of integrative processes. Journal of Personality, 63(3), 397-427.

Ryan, R. M., \& Deci, E. L. (2000a). Self-determination theory and the facilitation of intrinsic motivation, social development, and well-being. The American psychologist, 55(1), 68-78.

Ryan, R. M., \& Deci, E. L. (2000b). Intrinsic and extrinsic motivations: Classic definitions and new directions. Contemporary Educational Psychology, 25(1), 54-67. 
Ryan, R. M., \& Deci, E. L. (2002). Overview of self-determination theory: An organismic dialectical perspective. In E. L. Deci, \& R. M. Ryan (Eds.), Handbook of self-determination research (pp. 3-33). Rochester, NY: University of Rochester Press. Ryan, R. M. (1982). Control and information in the intrapersonal sphere: An extension of cognitive evaluation theory. Journal of Personality and Social Psychology, 43(3), 450-461.

Schaubroeck, J., Lam, S. S. K., \& Cha, S. E. (2007). Embracing transformational leadership: Team values and the impact ofleader behavior on team performance. Journal of Applied Psychology, 92, 1020-1030.

Schaufeli, W. B., Bakker, A. B., \& Salanova, M. (2006). The measurement of work engagement with a short questionnaire: A cross-national study. Educational and Psychological Measurement, 66(4), 701-716.

Schaufeli, W. B., \& Salanova, M. (2007). Work engagement: An emerging psychological concept and its implications for organizations. In D. D. S. Gilliland, \& D. P. Skarlicki (Eds.), Research in social issues in management: Managing social and ethical issues in organizations (pp. 135-177). Greenwich, CT: Information Age Publishers.

Schaufeli, W. B., Salanova, M., González-Romá, V., \& Bakker, A. B. (2002). The measurement of engagement and burnout: A two sample confirmatory factor analytic approach. Journal of Happiness studies, 3(1), 71-92.

Schyns, B., \& Felfe, J. (2006). The personality of followers and its effect on the perception of leadership. Small Group Research, 37(5), 522-539.

Shamir, B., House, R. J., \& Arthur, M. B. (1993). The motivational effects of charismatic leadership: A self-concept based theory. Organization Science, 4(4), 577-594.

Sheldon, K. M., \& Elliot, A. J. (1999). Goal striving, need satisfaction, and longitudinal well-being: The selfconcordance model. Journal of Personality and Social Psychology, 76(3), 482-497.

Stone, A. G., Russell, R. F., \& Patterson, K. (2004). Transformational versus servant leadership: A difference in leader focus. Leadership \& Organization Development Journal, 25(4), 349-361.

Tims, M., Bakker, A. B., \& Xanthopoulou, D. (2011). Do transformational leaders enhance their followers' daily work engagement? The Leadership Quarterly, 22(1), 121-131.

Tremblay, M. A., Blanchard, C. M., Taylor, S., Pelletier, L. G., \& Villeneuve, M. (2009). Work extrinsic and intrinsic motivation scale: Its value for organizational psychology research. Canadian Journal of Behavioural Science, 41(4), 213-226.

Trépanier, S.-G., Fernet, C., \& Austin, S. (2012). Social and motivational antecedents of perceptions of transformational leadership: A self-determination theory perspective. Canadian Journal of Behavioural Science, 44(4), 272-277.

Uhl-Bien, M., Riggio, R. E., Lowe, K. B., \& Carsten, M. K. (2014). Followership theory: A review and research agenda. The Leadership Quarterly, 25(1), 83-104.

Vallerand, R. J. (2000). Deci and Ryan's self-determination theory: A view from the hierarchical model of intrinsic and extrinsic motivation. Psychological Inquiry, 11(4), 312-318.

Vallerand, R. J., \& Blssonnette, R. (1992). Intrinsic, extrinsic, and amotivational styles as predictors of behavior: A prospective study. Journal of Personality, 60(3), 599-620.

Van Dierendonck, D. (2004). The construct validity of Ryff's Scales of Psychological Well-being and its extension with spiritual well-being. Personality and Individual Differences, 36(3), 629-643.

Wang, Z., \& Gagné, M. (2013). A Chinese-Canadian cross-cultural investigation of transformational leadership, autonomous motivation, and collectivistic value. Organizational Studies, 20(1), 134-142.

Wang, L., Hinrichs, K. T., Prieto, L., \& Black, J. A. (2010). The effect of followers' behavior on leader efficacy. Journal of Business and Management, 16(2), 139.

Williams, G. G., Gagné, M., Ryan, R. M., \& Deci, E. L. (2002). Facilitating autonomous motivation for smoking cessation. Health Psychology, 21(1), 40-50.

Wortman, M. (1982). Strategic management and changing leader-follower roles. The Journal of Applied Behavioural Science, 18(3), 371-383.

Cite this article: Chua J and Ayoko OB. 2021. Employees' self-determined motivation, transformational leadership and work engagement. Journal of Management \& Organization 27, 523-543. doi:10.1017/jmo.2018.74 